\title{
Arbuscular mycorrhizal symbiosis and active ingredients of medicinal plants: current research status and prospectives
}

\author{
Yan Zeng • Lan-Ping Guo • Bao-Dong Chen • \\ Zhi-Peng Hao • Ji-Yong Wang • Lu-Qi Huang • \\ Guang Yang $\cdot$ Xiu-Ming Cui $\cdot$ Li Yang . \\ Zhao-Xiang Wu $\cdot$ Mei-Lan Chen $\cdot$ Yan Zhang
}

Received: 23 August 2012 / Accepted: 31 January 2013 /Published online: 17 February 2013

(C) Springer-Verlag Berlin Heidelberg 2013

\begin{abstract}
Medicinal plants have been used world-wide for thousands of years and are widely recognized as having high healing but minor toxic side effects. The scarcity and increasing demand for medicinal plants and their products have promoted the development of artificial cultivation of medicinal plants. Currently, one of the prominent issues in
\end{abstract}

Yan Zeng and Lan-Ping Guo contributed equally to this work.

Y. Zeng $\cdot$ L.-P. Guo $\cdot$ L.-Q. Huang $(\bowtie) \cdot$ M.-L. Chen • Y. Zhang Chinese Materia Medica Resources Center, China Academy of Chinese Medical Sciences,

No. 16 Nanxiaojie, Dongzhimennei, Dongcheng District,

Beijing 100700, People's Republic of China

e-mail: huangluqi@263.net

B.-D. Chen · Z.-P. Hao $\cdot$ Z.-X. Wu

Soil Ecology and Ecosystem Restoration, State Key Laboratory of Urban and Regional Ecology, Research Center

for Eco-Environmental Sciences, Chinese Academy of Sciences, No. 18 Shuangqing Road, Haidian District,

Beijing 100085, People's Republic of China

\section{Y. Zeng $\cdot$ G. Yang}

State Key Laboratory of Earth Surface Processes and Resource Ecology, Beijing Normal University, No. 19 New Street Outside Street, Haidian District,

Beijing 100875, People's Republic of China

X.-M. Cui $\cdot$ L. Yang

Sanqi (Panax notoginseng) Academy of Sciences,

No. 99 Shaba North Road, Kaihua Town, Wenshan County,

Yunnan 663000, People's Republic of China

Y. Zeng $\cdot$ J.-Y. Wang

China National Corp. of Traditional \& Herbal Medicine, No. 15 East Mansion, Xisihuannorth Road, Haidian District, Beijing 100195, People's Republic of China medicinal cultivation systems is the unstable quality of the products. Arbuscular mycorrhiza (AM) affects secondary metabolism and the production of active ingredients of medicinal plants and thus influence the quality of herbal medicines. In this review, we have assembled, analyzed, and summarized the effects of AM symbioses on secondary metabolites of medicinal plants. We conclude that symbiosis of AM is conducive to favorable characteristics of medicinal plants, by improving the production and accumulation of important active ingredients of medicinal plants such as terpenes, phenols, and alkaloids, optimizing the composition of different active ingredients in medicinal plants and ultimately improving the quality of herbal materials. We are convinced that the AM symbiosis will benefit the cultivation of medicinal plants and improve the total yield and quality of herbal materials. Through this review, we hope to draw attention to the status and prospects of, and arouse more interest in, the research field of medicinal plants and mycorrhiza.

Keywords Arbuscular mycorrhizal symbiosis · Medicinal plants $\cdot$ Secondary metabolites $\cdot$ Active ingredients

\section{Introduction}

Arbuscular mycorrhizal (AM) fungi contribute greatly to crop productivity and ecosystem sustainability in new plant production strategies (Gianinazzi et al. 2010) and are essential for the sustainable management of agricultural ecosystems (Jeffries et al. 2003; Smith and Read 2008; Barrios 2007). They promote the accumulation of effective ingredients of medicinal plants, which has become a hot area of 
research lately. Mandala (Datura stramonium) and Schizonepeta (Schizonepeta tenuifolia) were the first medicinal plants shown to be affected by AM fungi (Wei and Wang 1989, 1991). A literature research for studies on the relationship between AM fungi and medicinal plants resulted in reports involving 50 species from 19 families (Table 1), including some commonly used medicinal plants such as Salvia miltiorrhiza, Glycyrrhiza inflata, Atractylodes macrocephala, Bupleuruin scorzonerifolium, Artemisia annua, and Atractylodes lancea. Some are also endangered herbs, such as Panax ginseng, Panax notoginseng, and Paris polyphylla var. Some medicinal plants are also used for food (or additives), such as Coriandrum sativum, Mentha arvensis, and Ocimum basilicum, oregano etc. Mycorrhiza-orientated research topics have included AM fungal resources, inoculation methods, as well as effects on the growth, development, and secondary metabolism (active ingredients) of medicinal plants. The active ingredients of medicinal plants are mostly plant secondary metabolites, the quality of which directly affects the quality of medicinal materials. These metabolites included terpenes (such as total essential oil, sesquiterpene, diterpenes), phenols (such as flavonoids or coumarin), and alkaloids (such as scopolamine, berberine, camptothecin).

A total of 47 papers have focused on the secondary metabolites of medicinal plants associated with AM fungi. Research objectives have been not only to use $\mathrm{AM}$ to increase the yield, but also to improve the quality of medicinal materials. While many studies have shown that mycorrhiza play positive roles in improving the contents of secondary metabolites in medicinal plants (Table 2), in-depth research is still required to understand the mechanisms by which AM fungi affect the accumulation of effective ingredients in medicinal plants (Toussaint 2007). Here, we summarize the current research progress on the relationship between $\mathrm{AM}$ and secondary metabolites of medicinal plants. We consider that this research area is very important, and that the application of issuing knowledge can have great potential in improving the quality of medicinal materials.

\section{Impacts of the arbuscular mycorrhizal symbiosis on secondary metabolites contents in medicinal plants}

Many different secondary metabolites with different functions are produced during the growth and development of plants. Symbioses between plants and AM fungi can promote the accumulation in medicinal plants of several secondary metabolites which play important roles in treating human diseases (Tables 1 and 2).
Terpenes

Terpenes and terpenoids (or isoprenoids) are the primary constituents of the essential oils of many types of plants and flowers. The contents of some derivatives are high in plants that are associated with AM fungi (Janardhanan and Abdul-Khaliq 1995; Maier et al. 1999; Gupta et al. 2002; Akiyama and Hayashi 2002). In medicinal plants, essential oils are mixtures of some low-molecular weight terpenoids which are often the active ingredients of herbal medicines. Many studies have shown that the contents of essential oils in medicinal plants increase after the plants have been inoculated with AM fungi (Table 2). However, most of these medicinal plants, such as mint, oregano, basil, dill, orchid celery, fennel, and agastache, are not yet considered as medicinal raw materials and food additives (e.g., spices).

Some important and unique active ingredients or aroma components in certain medicinal plants have unique functions, and this has become the focus of many researches on the effects of AM symbiosis in medicinal plants. Contents of these unique ingredients can be used as standards for the quality of medicinal plants, such as levels of limonene and carvone in dill (Kapoor et al. 2002a), thymol in carum (Kapoor et al. 2002a), geraniol and linalool in coriander (Kapoor et al. 2002b), anethol in fennel (Kapoor et al. 2004), sesquiterpene lactones in Arnica (Jurkiewicz et al. 2010), and artemisinin in A. апnиа (Kapoor et al. 2007; Chaudhary et al. 2008; Huang et al. 2011). Previous research has shown that the AM symbiosis can promote the production of specific secondary metabolites in specific medicinal plants. For example, Liu et al. (2007) have found that the content of glycyrrhizic acid, a triterpenoid saponin and an important active ingredient in glycyrrhiza in plants, increases with the AM symbiosis in liquorice plants by $0.38-1.07$-fold after 4 months of cultivation and by 1.34 1.43 -folds after 30 months of cultivation compared with non-mycorrhizal control plants (Liu et al. 2007). Researchers have also studied the impact of the AM symbiosis on transplanted tissue cultured medicinal plants; AM fungal inoculation increases, for example, the content of essential oil in oregano plants derived from micropropagated seedlings (Morone Fortunato and Avato 2008).

Phenolic compounds

Structurally, phenolic compounds contain an aromatic group, one or more hydroxyl group(s), and other groups. AM fungi can induce defence-related compounds, including the production of phenolics, in plants (Volpin et al. 1994; Harrison 1999). Phenolic compounds, such as flavonoids and coumarin, are the active ingredients in many medicinal plants. Researchers have found that the content of flavonoids in Bupleurum chinense, S. miltiorrhiza, Ginkgo biloba 


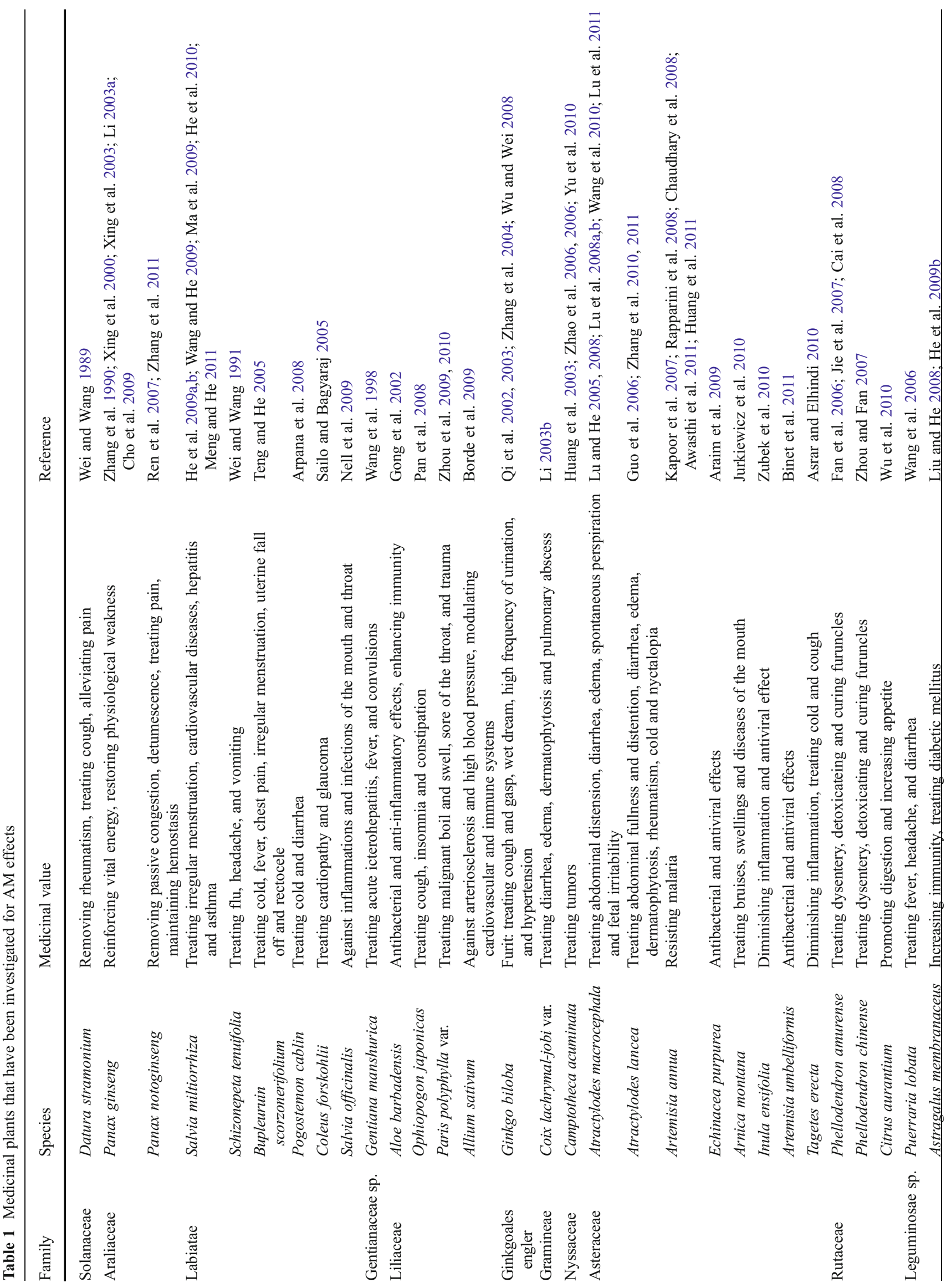




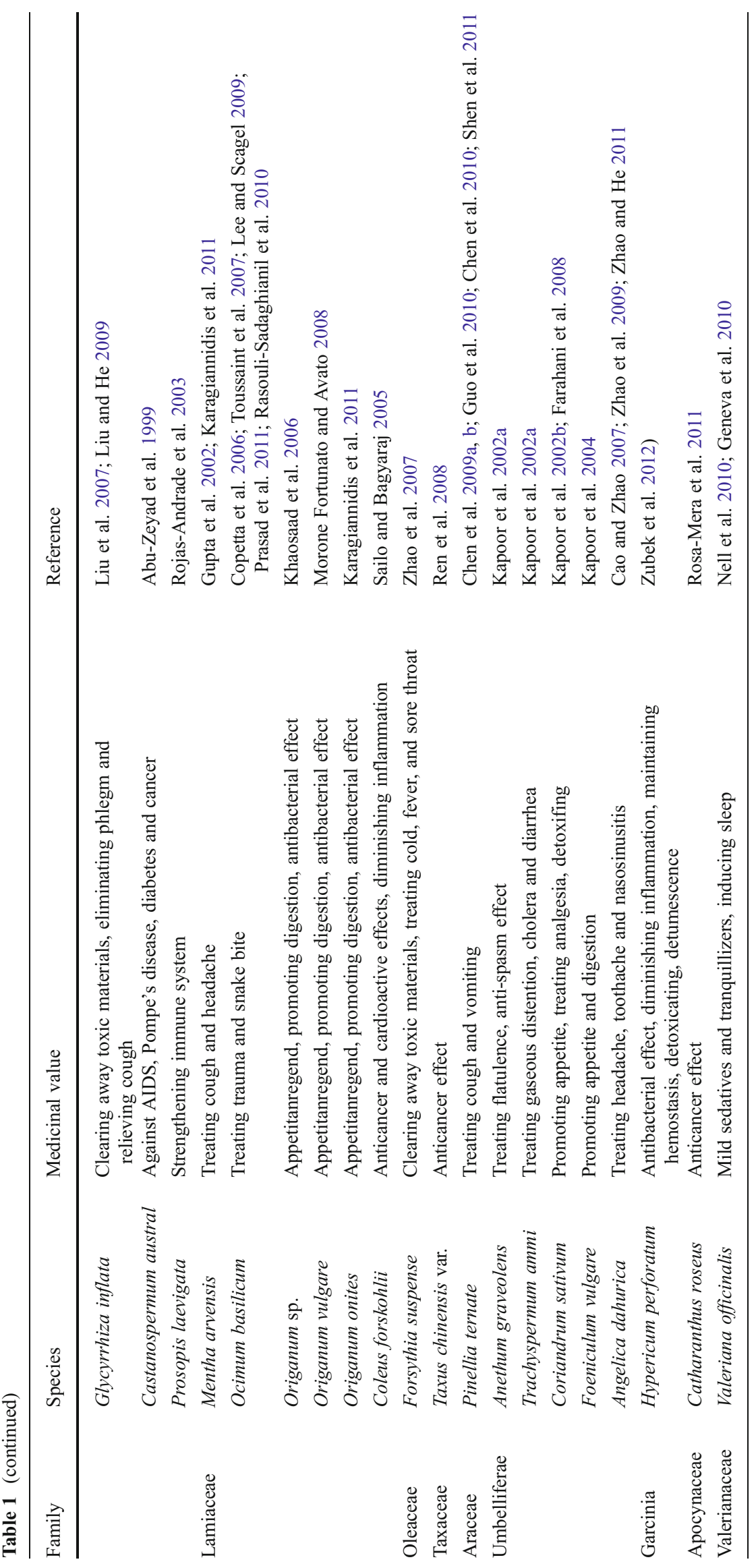




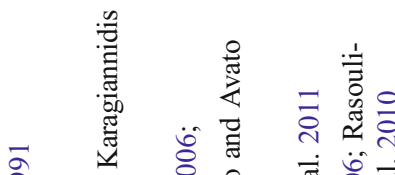

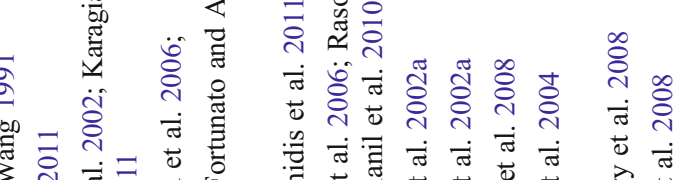

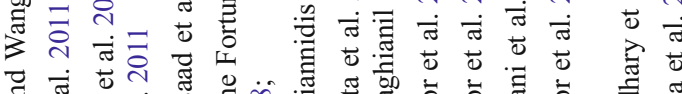

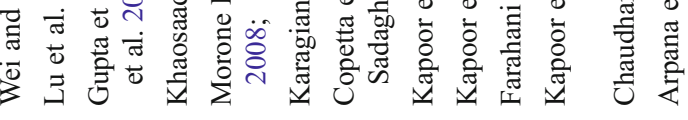

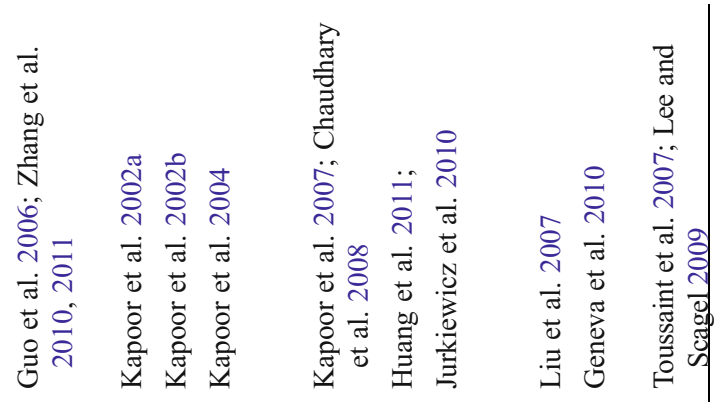

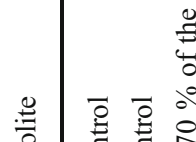

$\rightleftarrows$

焉

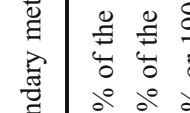

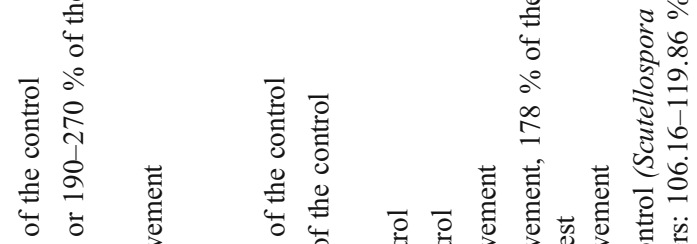

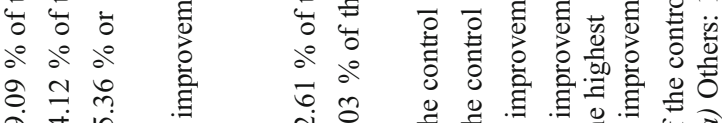

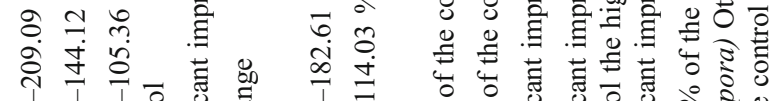
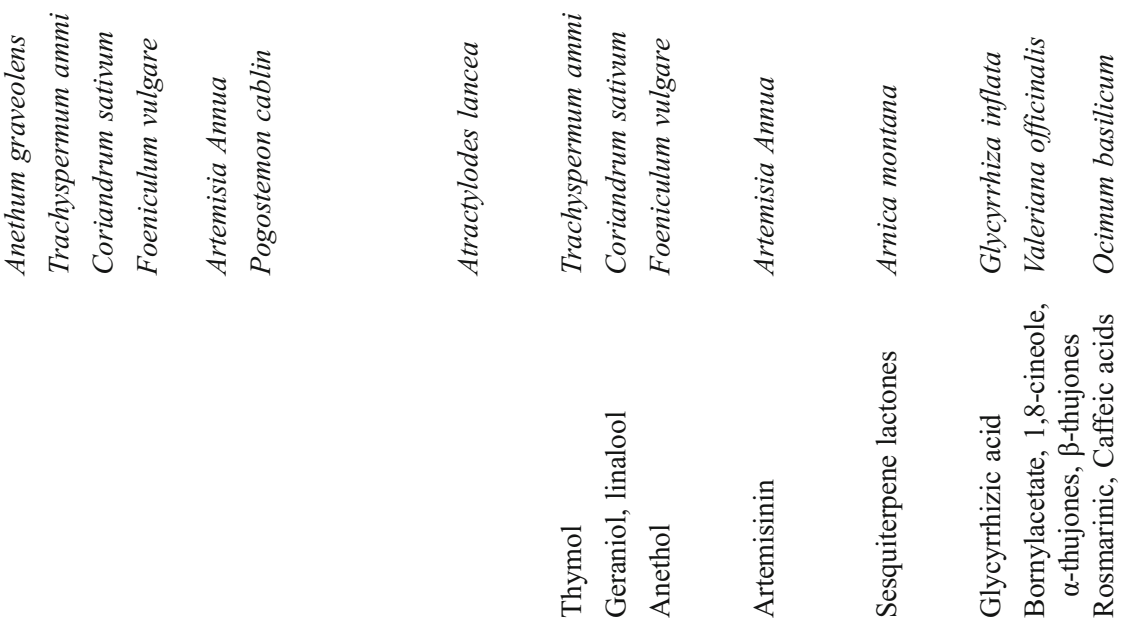


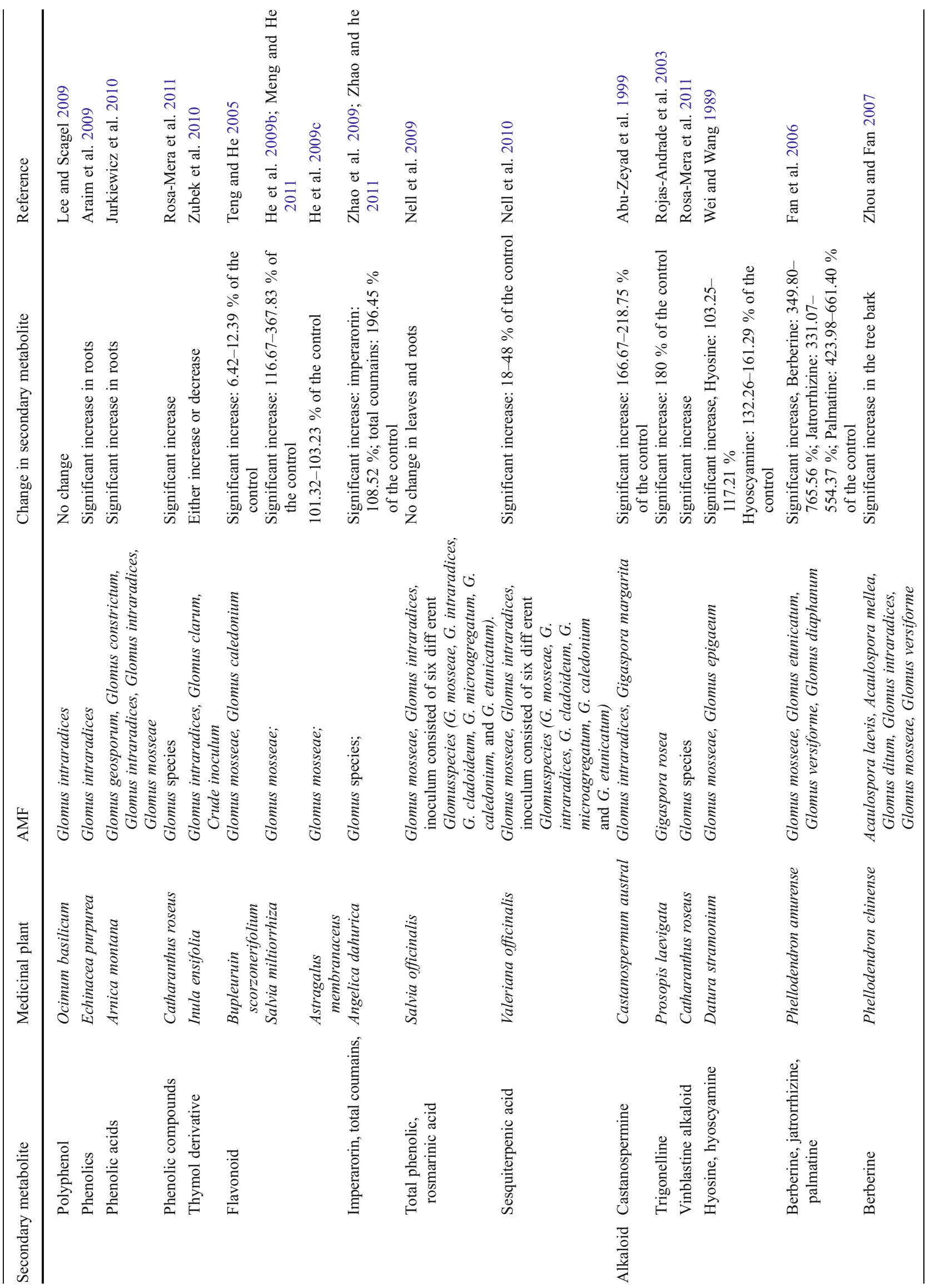




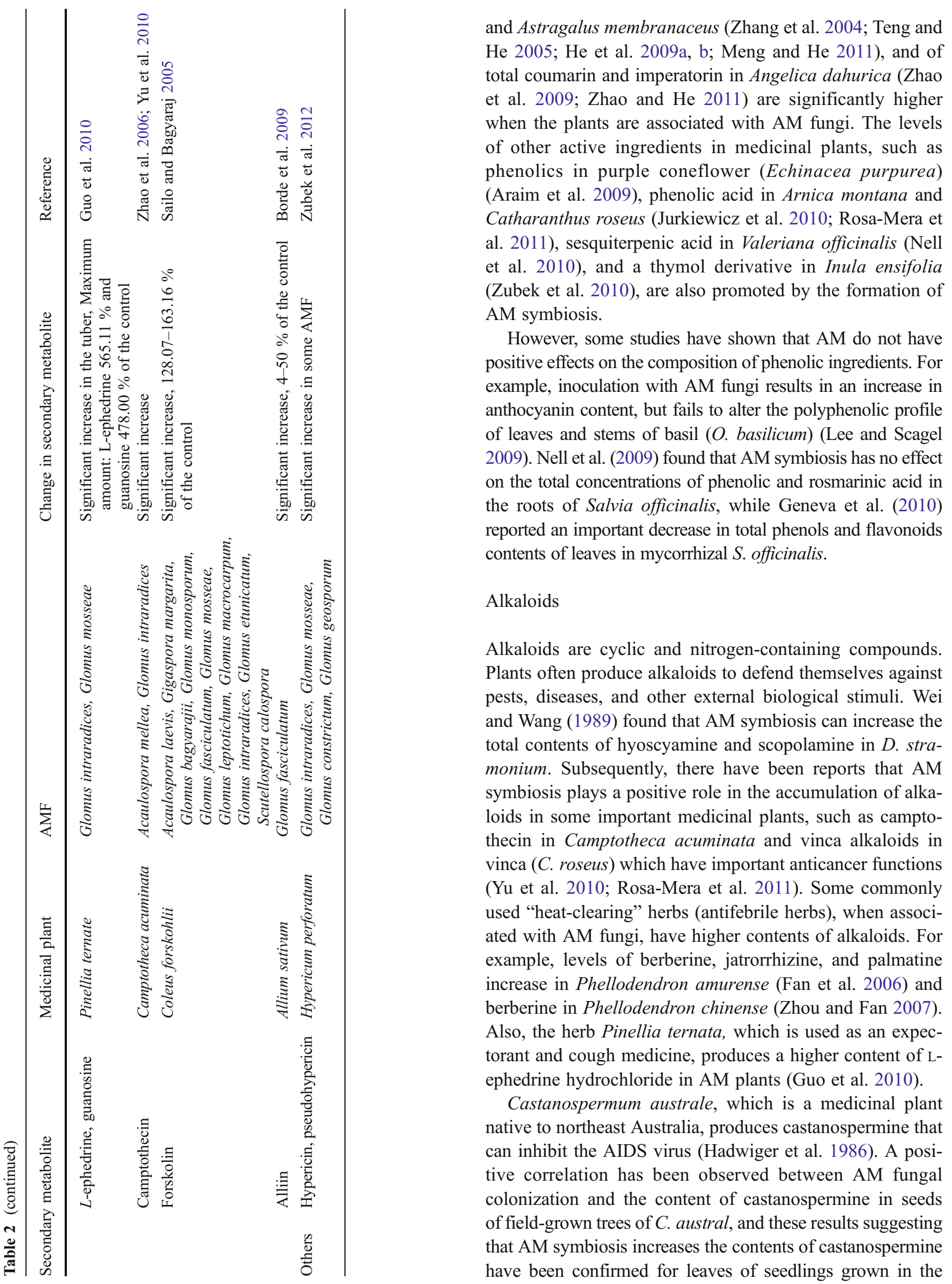


greenhouse, irrespective of $\mathrm{P}$ treatments (Abu-Zeyad et al. 1999). Coleus (Coleus forskohlii) is an important medicinal plant with alkaloids and forskolin in the root system. It is extensively used to treat heart diseases, glaucoma, asthma, and certain types of cancers (Shah et al. 1980). In greenhouse studies conducted to investigate the effectiveness of $11 \mathrm{AM}$ fungi on coleus production, results showed that AM formation increases the content of forskolin (Sailo and Bagyaraj 2005). In studies of changes in secondary metabolites of the semiarid legume Prosopis laevigata. Johnst in an in vitro system, Rojas-Andrade et al. (2003) found that the root concentration of trigonelline, another medicinal alkaloid, was already 1.8fold higher in plants during the presymbiotic phase of AM development. Finally, garlic (Allium sativum), which is a very popular cooking additive, is also known as a folk medicine commonly used against arteriosclerosis and high blood pressure. One compound in garlic, allicin (converted from alliin by the enzyme allinase), has antioxidative and anticancerogenic properties, and is capable of modulating the functions of the cardiovascular and immune systems (Harris et al. 2001). Borde et al. (2009) found that garlic plants inoculated with mycorrhizal fungi have higher levels of alliin and allinase activities than non-inoculated garlic plants under field conditions.

\section{Others}

Hypericum perforatum is a valuable medicinal plant species which produces the important active ingredients hypericin and pseudohypericin, polycyclic aromatic diones with antiviral activity and inhibitory effects towards AIDS. Zubek et al. (2012) have shown that the contents of hypericin and pseudohypericin increase significantly in plants in the presence of AM symbiosis.

\section{Effect of AM symbiosis on chemical composition of secondary metabolites}

While AM symbiosis can significantly increase the contents of some secondary metabolites of medicinal plants, it is not clear whether the composition of the secondary metabolites in medicinal plants also changes. There are contrasting reports that AM symbiosis can change or optimize the chemical composition in medicinal plants. No differences were found in essential oil components between mycorrhizal and nonmycorrhizal plants of A. lancea from the region of Maoshan, the production area of Daodi medicinal materials used as a synonym of high-quality Chinese herbal medicine (Huang et al. 2004). Likewise, mycorrhizal oregano (Origanum vulgare) showed a chemical profile of essential oils which was comparable to that of control plants, with carvacrol as the main compound (Morone Fortunato and Avato 2008). In contrast, Karagiannidis et al. (2011) found that AM fungal colonization increases the contents and changes the composition of essential oils in oregano (Origanum onites) and mint (Menta viridis). Geneva et al. (2010) also observed that AM formation in $S$. officinalis changes the composition of essential oils, and promotes the relative quantities of bornylacetate, 1,8-cineole, $\alpha$ thujones and $\beta$-thujones. Mycorrhizal roots of Artemisia umbelliformis are reported to have a significantly increased percentage of E-ocimene and reduced percentages of E-2decenal and (E, E)-2-4-decadienal (Binet et al. 2011), while AM fungal inoculation increases not only essential oil concentrations in coriander (C. sativum) but also geraniol and linalool, which are landmark components for quality evaluation (Kapoor et al. 2002b). Similarly, AM symbiosis significantly increases the concentrations of not only the essential oils but also the important active ingredient anethol in fennel (Foeniculum vulgare) (Kapoor et al. 2004).

\section{Differential effects of AM fungi in promoting the accumulation of secondary metabolites of medicinal plants}

The degree of influence of different AM fungi on the same medicinal plant or of the same AM fungus on different medicinal plants can vary. Jurkiewicz et al. (2010) reported that inocula composed of different AM fungi differed not only in their effectiveness in establishing symbiosis and promoting growth of $A$. montana, but also in the degree to which they increased plant contents in phenolic acids and sesquiterpene lactones. Similar results have been obtained by several researchers. For example, when Glomus mosseae BEG 12, Gigaspora margarita BEG 34, and G. rosea BEG 9 were inoculated onto basil plants (O. basilicum var.), essential oil contents were significantly incremented, but to different extents depending on the AM fungus, with G. rosea BEG 9 having the greatest effect (Copetta et al. 2006). AM symbiosis significantly increased the contents of essential oils in dill, carum, and coriander, and G. fasciculatum appeared to be more effective than Glomus macrocarpum (Kapoor et al. 2002a, b). Rasouli-Sadaghianil et al. (2010) also reported that G. fasciculatum may have a higher symbiotic potential in increasing essential oil contents in basil. On the other hand, G. macrocarpum was the more effective of the two fungi in enhancing the concentration of artemisinin in A. аnnua (Chaudhary et al. 2008).

Since different AM fungi can promote the accumulation of secondary metabolites to different extents in medicinal plant species, large scale screening of a range of AM fungi is required in order to obtain an ideal strain. When 11 different AM fungal species were evaluated for their symbiotic effects on patchouli (Pogostemon cablin) (Arpana et al. 2008) or C. forskohlii (Sailo and Bagyaraj 2005) in the greenhouse, it was found that all enhanced essential oil contents in P. cablin and forskolin in $C$. 
forskohlii. However, Glomus etunicatum gave the most promising results with Pogostemon (Arpana et al. 2008), and G. bagyarajii with $C$. forskohlii (Sailo and Bagyaraj 2005). Other work has shown that the production of secondary metabolites in different parts of a medicinal plant may either be enhanced or reduced depending on which AM fungus is associated. For example, AM fungal species specificity was observed in stimulating the production of thymol derivatives in the roots of $I$. ensifolia inoculated with four different AM fungi. Root content of 7-isobutyryloxythymol methyl ether increased after inoculation with $G$. clarum, but not after inoculation with $G$. intraradices (Zubek et al. 2010). On the contrary, all four AM fungi caused decreases in the shoot content of 7-isobutyryloxythymol methyl ether.

While knowledge about the impact of different AM fungi on active ingredients of medicinal plants is the basis for their screening vis-a-vis a specific medicinal plant, synergistic effects with other microorganisms also need to be considered due to the complexity of the soil environment. Therefore, future screening of AM fungal inocula should be performed in the context of a variety of microorganisms. In a study to determine the effect of four different AM fungi and two free living nitrogen fixing bacteria (NFB) on the content of artemisinin in A. annua inoculated alone or in combination, plants co-inoculated with G. mosseae and a Bacillus subtilis strain produced 25.5-103.2\% more artemisinin than in other treatments, indicating a synergistic effect between $G$. mosseae and B. subtilis (Awasthi et al. 2011). Synergy has also been observed between $G$. fasciculatum and a beneficial Pseudomonas in improving yield and forskolin content of $C$. forskohlii tubers under field conditions (Singh et al. 2013).

\section{Mechanism by which AM symbiosis promotes secondary metabolism of medicinal plant}

The increase in concentrations of several groups of plant metabolites as a result of AM establishment has, in general, been considered as a defense response to fungal colonization. However, it is not clear how AM fungi trigger changes in the concentrations of phytochemicals in plant tissues (Toussaint et al. 2007), and there are only a few reports about the molecular mechanism(s) by which AM symbiosis promotes the accumulation of secondary metabolites.

Effect of interaction of $\mathrm{P}$ fertilizer and AM symbiosis on accumulation of secondary metabolites of medicinal plants

AM fungi promote the absorption of $\mathrm{P}$ by plants (Smith and Read 2008). Castanospermum austral plants treated with $P$ and those inoculated with AM fungi have similar contents of alkaloids (castanospermine) in their leaves. The fact that $\mathrm{P}$ treatment significantly increases alkaloid content of both non-mycorrhizal and mycorrhizal plants indicates that $\mathrm{P}$ nutrition may play a direct role in increasing the contents of secondary metabolites (Abu-Zeyad et al. 1999). Kapoor et al. (2004) obtained similar results for the accumulation of essential oil in fennel. Nell et al. (2009) found that full phosphorus treatment leads to a 1.2-fold increase in total phenolic and rosmarinic acid concentrations in the leaves of S. officinalis, as compared with a half phosphorus treatment, AM fungal inoculation, or control plants, which suggests that secondary metabolite contents increase only when $\mathrm{P}$ is supplemented in a sufficient amount. However, the same authors (Nell et al. 2010) observed either unchanged or significantly decreased contents of sequiterpenic acid in different genotypes of $V$. officinalis when plants were treated with P. Therefore, the effects of $\mathrm{P}$ on secondary metabolites may vary between different medicinal plants.

On the other hand, Toussaint et al. (2007) reported that although high $\mathrm{P}$ amendments to non-mycorrhizal plants increase rosmarinic and caffeic acid concentrations in sweet basil ( $O$. basilicum), the increased production of rosmarinic and caffeic acids in the shoots of AM plants is not solely due to improved $\mathrm{P}$ nutrition. Observations in mycorrhizal $A$. annua suggest that the increase in artemisinin concentration may not be entirely attributed to enhanced $\mathrm{P}$ nutrition (Chaudhary et al. 2008; Kapoor et al. 2007). Khaosaad et al. (2006) also found that essential oil concentration significantly increases in two oregano genotypes associated with G. mosseae, but the levels of essential oil in plants treated with $\mathrm{P}$ are not changed, which indicates that the increase in essential oil concentration in mycorrhizal oregano plants is not due to an improved $\mathrm{P}$ nutrition, but directly depends on association with the AM fungus.

\section{Effect of AM symbiosis on characteristics of medicinal} plants

Essential oil is synthesized in the glandular trichome of plant leaves and so there is usually a strong positive correlation between the density of glandular trichomes and the levels of accumulated essential oil or other secondary metabolites in plants such as $O$. basilicum, Origanum sp, A. annua, and $M$. arvensis. Interestingly, AM symbiosis formation increased the density of glandular trichome on the upper leaf epidermis of $O$. vulgare-micropropagated seedlings (Morone Fortunato and Avato 2008), and Copetta et al. (2006) have suggested that significantly increased levels of essential oil in O. basilicum colonized by three different AM fungi result from significantly larger numbers of peltate glandular trichomes on the basal and central leaf zones (Copetta et al. 2006). In line with this, Kapoor et al. (2007) found that two AM fungi increased the density of foliar glandular trichomes in A. annua, and that a 
strong correlation existed between the density of glandular trichomes on leaves and artemisinin concentrations.

\section{Discussion and perspectives}

There have been several previous evaluations and summaries about the advantages, prospects, and feasibility of introducing AM fungi into the process of cultivation of medicinal plants (Guo et al. 2006; Zeng et al. 2007; Yang et al. 2008; Xiao et al. 2011). The growing shortage of wild medicinal plant resources may provoke a crisis based on a blind pursuit for total yield without considering the quality of the medicinal plants. The challenge is to increase total yield while maintaining or improving quality assurance. The quality of herbal material in terms of active ingredients is influenced not only by abiotic factors such as light, temperature, humidity, soil fertility, and cultivation techniques, but also biotic factors such as herbivor attack, disease-related stimuli, and mutual symbioses with rhizobium and mycorrhizal fungi (Szakiel et al. 2011a, b). The positive role of AM symbiosis in plant growth, disease resistance, and both yield and quality of medicinal materials makes AM fungi potential alternatives to existing methods for promoting growth of some important medicinal herbs, especially since natural ways of growing such crops are currently highly sought after in the herbal industry (Toussaint et al. 2007).

In this paper, we have tried to provide a comprehensive review of information available about research on AM and secondary metabolites of medicinal plants, in order to set a basis for future work. The mechanisms by which AM fungi trigger changes in the concentration of phytochemicals in plant tissues are not yet well understood (Toussaint 2007). AM symbiosis activity promotes absorption of $\mathrm{P}, \mathrm{N}$, and other mineral nutrients, and thus contributes to the accumulation of secondary metabolites in plants. For example, isoprenoid biosynthesis requires acetyl-CoA, ATP, and NADPH and is dependent on the concentration of inorganic phosphorus in the plant, so that terpenoid derivative essential oils are enhanced through better plant absorption of $\mathrm{P}$ (Loomis and Corteau 1972). Tyrosine and phenylalanine are important precursors of some secondary metabolites, such as rosmarinic and caffeic acids (Petersen and Simmonds 2003). Consequently, AM symbiosis can enhance the synthesis of certain amino acids and contribute to the accumulation of specific metabolites by promoting $\mathrm{N}$ uptake (Smith and Read 1997; Toussaint et al. 2004). Some research has also shown that symbiosis with AM fungi results in the increase of terpenoids and phenolic acids, which may result from increased absorption of mineral nutrients, especially $\mathrm{P}$ and N (Kapoor et al. 2002a, b; Toussaint et al. 2007). Finally, changes in the secondary metabolites of mycorrhizal plants may result from changes in levels of phytohormones like cytokinin or gibberellin (Allen et al. 1980, 1982; Copetta et al. 2006; Kapoor et al. 2007; Toussaint 2007). However, these and other possibilities all remain to be verified (Toussaint 2007).

The AM symbiosis has obvious advantages in alleviating stresses under poor climate and soil conditions (such as fertilizer shortage and water deficiency) like those met in the cultivation area of $G$. inflata where plants face nutrient stress, water stress, and salt stress under desertification conditions and where AM fungi have the potential to significantly improve the yield and quality of licorice (Liu et al. 2007). In this context, it is necessary to perform studies under environmental conditions inherent to those of the cultivation area in order to obtain the ideal conditions under which AM fungi can promote the productivity of medicinal plants. The use of agricultural facilities to control environmental factors and provide favorable conditions for the symbiosis between medicinal plants and AM fungi will favor the yield and quality of medicinal materials, under specific soil and climate conditions.

In conclusion, in order to further knowledge about the organic production of herbal materials, much effort is needed in research on the role of AM fungi and the AM symbiosis and the use of mycorrhizal technology in the cultivation of medicinal plants. To meet these objectives, future research priorities should focus on: (1) selection efficient AM fungal strains adapted to production conditions, (2) procedures for the production of seedlings of medicinal plants with mycorrhiza, (3) intensive cultivation of medicinal plants and the production of organic medicinal materials, and (4) mechanisms by which AM fungi change the contents of active ingredients in medicinal plants.

Acknowledgments This study was supported by the National Natural Science Foundation of China (NSFC) (81130070, 81072989, and 41101245), Special Industry Research Project by State Administration of Traditional Chinese Medicine (201107009), International Technical Cooperation Project (2009DFA31660), Project of Science and Technology Plan of Yunnan Province (2008IF025-4) and Research Project of Academy of Chinese Medical Sciences of China (ZZ20090302).

\section{References}

Abu-Zeyad R, Khan AG, Khoo C (1999) Occurrence of arbuscular mycorrhiza in Castanospermum australe A. Cunn. \& C. Fraser and effects on growth and production of castanospermine. Mycorrhiza 9:111-117

Akiyama K, Hayashi H (2002) Arbuscular mycorrhizal funguspromoted accumulation of two new triterpenoids in cucumber roots. Biosci Biotechnol Biochem 66(4):762-769

Allen MF, Moore TS, Christensen M (1980) Phytohormone changes in Bouteloua gracilis infected by vesicular-arbuscular mycorrhizae. I. Cytokinin increases in the host plant. Can J Bot 58:371-374

Allen MF, Moore TS, Christensen M (1982) Phytohormone changes in Bouteloua gracilis infected by vesicular-arbuscular mycorrhizae. 
II. Altered levels of gibberellin-like substances and abscisic acid in the host plant. Can J Bot 60:468-471

Araim G, Saleem A, Arnason JT, Charest AC (2009) Root colonization by an arbuscular mycorrhizal (AM) fungus increases growth and secondary metabolism of purple coneflower, Echinacea purpurea (L.) Moench. J Agric Food Chem 57:2255-2258

Arpana J, Bagyaraj DJ, Prakasa Rao EVS, Parameswaran TN, Abdul Rahiman BA (2008) Symbiotic response of patchouli [Pogostemon cablin (Blanco) Benth.] to different arbuscular mycorrhizal fungi. Adv Environ Biol 2(1):20-24

Asrar AWA, Elhindi KM (2010) Elhindi. Alleviation of drought stress of marigold (Tagetes erecta) plants by using arbuscular mycorrhizal fungi. Saudi J of Biol Sci 18(1):93-98

Awasthi A, Bharti N, Nair N, Singh R, Shukla AK, Gupta MM, Darokar MP, Kalra A (2011) Synergistic effect of Glomus mosseae and nitrogen fixing Bacillus subtilis strain Daz26 on artemisinin content in Artemisia annua L. Appl Soil Ecol 49:125-130

Barrios E (2007) Soil biota, ecosystem services and land productivity. Ecol Econ 64:269-285

Binet MN, Van Tuinen D, Deprêtre N, Koszela N, Chambon C, Gianinazzi S (2011) Arbuscular mycorrhizal fungi associated with Artemisia umbelliformis Lam, an endangered aromatic species in Southern French Alps, influence plant P and essential oil contents. Mycorrhiza 21:523-535

Borde M, Dudhane M, Jite PK (2009) Role bioinoculant (AM fungi) increasing in growth, flavor content and yield in Allium sativum L. under field condition. Not Bot Hort Agrobot Cluj 37(2):124-128

Cai BY, Jie WG, Ge JP, Yan XF (2008) Molecular detection of the arbuscular mycorrhizal fungi in the rhizosphere of Phellodendron amurense. Mycosystema 27(6):884-893

Cao DX, Zhao JL (2007) The investigation of arbuscular mycorrhizal fungi and soil factors from the rhizospere of medicinal plant Angelica dahurica. Acta Agr Boreali-Sin 22:47-50

Chaudhary V, Kapoor R, Bhatnagar AK (2008) Effectiveness of two arbuscular mycorrhizal fungi on concentrations of essential oil and artemisinin in three accessions of Artemisia annua L. Appl Soil Ecol 40:174-181

Chen LT, Guo QS, Liu ZY (2009a) Colonization pattern and dynamic change of arbuscular mycorrhizal fungi in Pinellia ternate. Guizhou Agr Sci 37(2):37-39

Chen LT, Liu ZY, Guo QS, Zhu GS (2009b) Advances in studies on arbuscular mycorrhizas in medicinal plants. Chin Tradi Herb Drugs 40(1):156-160

Chen LT, Guo QS, Liu ZY (2010) Arbuscular mycorrhiza of cultivated and wild Pinellia ternate. Chin J Chin Mater Med 35(4):405-410

Cho EJ, Lee DJ, Wee CD, Kim HL, Cheong YH, Cho JS, Sohn BK (2009) Effects of AM FUNGI inoculation on growth of Panax ginseng C.A. Meyer seedlings and on soil structures in mycorrhizosphere. Sci Hortic 122(4):633-637

Copetta A, Lingua G, Berta G (2006) Effects of three AM fungi on growth, distribution of glandular hairs, and essential oil production in Ocimum basilicum L. var. Genovese. Mycorrhiza 16:485-494

Fan JH, Yang GT, Mu LQ, Zhou JH (2006) Effect of AM fungi on the content of berberine, jatrorrhizine and palmatine of Phellodendron amurense seedings. Prot Forest Sci Technol 5:24-26

Farahani HA, Lebaschi MH, Hamidi A (2008) Effects of arbuscular mycorrhizal fungi, phosphorus and water stress on quantity and quality characteristics of coriander. J Adv Nat Appl Sci 2(2):55-59

Geneva MP, Stancheva IV, Boychinova MM, Mincheva NH, Yonova PA (2010) Effects of foliar fertilization and arbuscular mycorrhizal colonization on Salvia officinalis L. growth, antioxidant capacity, and essential oil composition. J Sci Food Agric 90:696-702

Gianinazzi S, Gollotte A, Binet MN, Tuinen DV, Redecker D, Wipf D (2010) Agroecology: the key role of arbuscular mycorrhizas in ecosystem services. Mycorrhiza 20:519-530
Gong MQ, Wang FZ, Chen Y (2002) Study on application of arbuscular-mycorrhizas in growing seedling of Aloe vera. J Chin Med Mater 25(1):1-3

Guo LP, Wang HG, Hang LQ (2006) Effects of arbuscular mycorrhizae on growth and essential oil of Atractylodes lancea. Chin J Chin Mater Med 31(8):1491-1495

Guo QS, Chen LT, Liu ZY (2010) Study on influence of arbuscular mycorrhizal fungi on Pinellia ternata yield and chemical composition. Chin J Chin Med 35(3):333-338

Gupta ML, Prasad A, Ram M, Kumar S (2002) Effect of the vesiculararbuscular mycorrhizal (VAM) fungus Glomus fasciculatum on the essential oil yield related characters and nutrient acquisition in the crops of different cultivars of menthol mint (Mentha arvensis) under field conditions. Bioresour Technol 81(1):77-79

Hadwiger A, Neimann H, Kaebisch A, Bauer H, Tamura T (1986) Appropriate glucosylation of the FMS gene product is a prerequisite for its transforming potency. EMBO J 5:689-694

Harris JC, Cottrell S, Plummer S, Lloyd D (2001) Antimicrobial properties of Allium sativum (garlic). Appl Microbiol Biotechnol $57: 282-286$

Harrison M (1999) Molecular and cellular aspects of the arbuscular mycorrhizal symbiosis. Annu Rev Plant Biol 50:361-389

He XL, Li J, Gao AX, Zhao LL, Zao JL (2009a) Effects of different host plants on the development of AM fungi in the rhizospere of Salvia miltiorrhiza. J Hebei Univers 29(5):533-537

$\mathrm{He}$ XL, Li J, He C (2009b) Effects of AM fungi on the chemical components of Salvia miltiorrhiza Bge. Chin Agr Sci Bull 25(14):182-185

He XL, Liu T, Zhao LL (2009c) Effects of inoculating AM fungi on physiological characters an nutritional components of Astragalus membranaceus under different $\mathrm{N}$ application levels. Chin J Appl Ecol 20(9):2118-2122

He XL, Wang LY, Ma J, Zhao LL (2010) AM fungal diversity in the rhizosphere of Salvia miltiorrhiza in Anguo city of Hebei province. Biodiv Sci 18(2):187-194

Huang YF, Li HH, Chen HY, Li Y (2003) Preliminary study on the mycorrhiza inoculation on the seeding of camptotheca acuminate. Guangdong ForestSci Technol 19(1):40-42

Huang LQ, Chen ML, Xiao PG (2004) The modern biological basis and model hypothesis on the research of genuineness of Chinese herbal medicine. Chin J Chin Mater Med 29(6):494-496

Huang JH, Tan JF, Jie HK, Zeng RS (2011) Effects of invoculating arbuscular mycorrhizal fungi on Artemisia annua growth and its officinal components. Chin J Appl Ecol 22(6):1443-1449

Janardhanan KK, Abdul-Khaliq K (1995) Influence of vesicular arbuscular mycorrhizal fungi on growth and productivity of German chamomile in alkaline usar soil. In: Adholeya A, Singh S (eds) Mycorrhizae: Biofertilizers for the Future. Tata Energy Research InstituteNew, Delhi, pp 410-412

Jeffries P, Gianinazzi S, Peretto S, Turnau K, Barea JM (2003) The contribution of arbuscular mycorrhizal fungi in sustainable maintenance of plant health and soil fertility. Biol Fertil Soils 37:1-16

Jie WG, Cai BY, Ge JP, Yan XF (2007) Identification of arbuscular mycorrhizal fungi of Phellodendren amurense Rupr. Biotechnology 17(6):32-35

Jurkiewicz A, Ryszka P, Anielska T, Waligórski P, Białońska D, Góralska K, Michael MT, Turnau K (2010) Optimization of culture conditions of Arnica montana L.: effects of mycorrhizal fungi and competing plants. Mycorrhiza 20:293-306

Kapoor R, Giri B, Mukerji KG (2002a) Glomus macrocarpum: a potential bioinoculant to improve essential oil quality and concentration in Dill (Anethum graveolens L.) and Carum (Trachyspermum ammi (Linn.) Sprague). World J Microb Biot 18:459-463

Kapoor R, Giri B, Mukerji KG (2002b) Mycorrhization of coriander (Coriandrum sativum L.) to enhance the concentration and quality of essential oil. J Sci Food Agr 82:339-342 
Kapoor R, Giri B, Mukerji KG (2004) Improved growth and essential oil yield and quality in Foeniculum vulgare mill on mycorrhizal inoculation supplemented with P-fertilizer. Bioresour Technol 93:307-311

Kapoor R, Chaudhary V, Bhatnagar AK (2007) Effects of arbuscular mycorrhiza and phosphorus application on artemisinin concentration in Artemisia annua L. Mycorrhiza 17:581-587

Karagiannidis N, Thomidisa T, Lazari D, Filotheou EP, Karagiannidou C (2011) Effect of three Greek arbuscular mycorrhizal fungi in improving the growth, nutrient concentration, and production of essential oils of oregano and mint plants. Sci Hortic 129:329-334

Khaosaad T, Vierheilig H, Nell M, Zitterl-Eglseer K, Novak J (2006) Arbuscular mycorrhiza alter the concentration of essential oils in oregano (Origanum sp., Lamiaceae). Mycorrhiza 16:443-446

Lee J, Scagel CF (2009) Chicoric acid found in basil (Ocimum basilicum L.) leaves. Food Chem 115(2):650-656

Li CX (2003a) Effect of vesicular-arbuscular mycorrhizal fungi on production of Ginseng. J Chin Med Mater 26(7):475-476

Li CX (2003b) Effects of infecting vesicular-arbuscular mycorrhiza on growth and development of Coix Lachryma-jobi L. J Shanxi Agr Univers 23(4):351-353

Liu T, He XL (2008) Research on the formation course of arbuscular mycorrhizae from Astragalus membranaceus (Fisch.) Bunge seedlings. J Hebei Fores Orc Res 23(3):311-314

Liu SL, He XL (2009) Effects of AM fungi on growth of Glycyrrhiza inflata Bat under water stress. J Nuc Agr Sci 23(4):692-696

Liu JN, Wu LJ, Wei SL, Xiao X, Su CX, Jiang P, Song ZB, Wang T, Yu ZL (2007) Effects of arbuscular mycorrhizal fungi on the growth, nutrient uptake and glycyrrhizin production of licorice (Glycyrrhiza uralensis Fisch). Plant Growth Regul 52(1):29-39

Loomis WD, Corteau R (1972) Essential oil biosynthesis. Rec Adv Phytochem 6:147-185

Lu YQ, He XL (2005) Effects of AM fungi on the chemical composition and growth amount of Atractylodes macrocephala koidz seedling on diffetent $\mathrm{N}$ levels. J Hebei Univers 25(6):650-653

Lu YQ, He XL (2008) Effects of AM fungi on photosynthetic pigment of Atractylodes macrocephala under different nitrogen levels. Acta Agr Bor Occi Sin 17(4):314-316

Lu YQ, Cui Y, He XL (2008a) Effects of AM fungi on biomass and nitrogen content of Atractylodes macrocephala under different nitrogen levels. J Henan Agr Sci 4:94-96

Lu YQ, He XL, Li LZ (2008b) Effects of AM fungi on leaf protective enzymes of Atractrlodes macrocephala under different nitrogen levels. Hubei Agr Sci 47(6):659-660

Lu YQ, Wang DX, Lu XL, Li LM, Li Y, He XL (2011) Effects of AM fungi on physiological character and nutritional component of Atractylodes macrocephala under different $\mathrm{N}$ levels. Acta Bot Bor Occi Sin 31(2):351-356

Ma J, He XL, Jiang ZM, Wang LY (2009) Influence of soil factors on arbuscular mycorrhizal fungal colonization of Salvia miltiorrhiza. Acta Agr Bor Occi Sin 18(5):194-198

Maier W, Schmidt J, Wray V, Walter MH, Strack D (1999) The arbuscular mycorrhizal fungus, Glomus intraradices, induces the accumulation of cyclohexenone derivatives in tobacco roots. Planta 207:620-623

Meng JJ, He XL (2011) Effects of AM fungi on growth and nutritional contents of Salvia miltiorrhiza Bge. under drought stress. J Agr Univ Hebei 34(1):51-61

Morone Fortunato I, Avato P (2008) Plant development and synthesis of essential oils in micropropagated and mycorrhiza inoculated plants of Origanum vulgare L. ssp. hirtum (Link) Ietswaart. Plant Cell Tiss Org 93:139-149

Nell M, Vötsch M, Vierheilig H, Steinkellner S, Zitterl-Eglseer K, Franz C, Novak J (2009) Effect of phosphorus uptake on growth and secondary metabolites of garden (Salvia officinalis L.). J Sci Food Agric 89:1090-1096
Nell M, Wawrosh C, Steinkellner S, Vierheilig H, Kopp B, Lössl A, Franz C, Novak J, Zitterl-Eglseer K (2010) Root solonization by symbiotic arbuscular mycorrhizal fungi increases sesquiterpenic acid concentrations in Valeriana of ficinalis L. Planta Med 76:393-398

Pan PL, Chen DQ, Chen YT, Zhou FM (2008) The research on the sift and germinate of AM FUNGI spore of Ophiopogon japonicas. Mod Chin Med 10(10):13-14

Petersen M, Simmonds MSJ (2003) Rosmarinic acid. Phytochemistry 62:121-125

Prasad A, Kumar S, Khaliq A, Pandey A (2011) Heavy metals and arbuscular mycorrhizal (AM) fungi can alter the yield and chemical composition of volatile oil of sweet basil (Ocimum basilicum L.). Biol Fert Soils 47(8):853-861

Qi GH, Zhang LP, Yang WL, Lu XR, Li CL (2002) Effects of arbuscular mycorrhizal fungi on growth and disease resistance of replanted ginkgo (Ginkgo biloba L.) seedlings. J Hebei Forest Orch Res 17(1):58-61

Qi GH, Zhang LP, Yang WL, Lv GY (2003) The effects of abruscular mycorrhiza fungi on ginkgo (Ginkgo biloba L.) in the field. Hebei Fruits 19(1):40-42

Rapparini F, Llusia J, Penuelas J (2008) Effect of arbuscular mycorrhizal (AM) colonization on terpene emission and content of Artemisia annua L. Plant Biol 10:108-122

Rasouli-Sadaghianil MH, Hassani A, Barin M, Danesh YR, Sefidkon F (2010) Effects of arbuscular mycorrhizal (AM) fungi on growth, essential oil production and nutrients uptake in basil. J Med Plants Res 4(21):2222-2228

Ren JH, Liu RX, Li YL (2007) Study on arbuscular mycorrhizae of Panax notoginseng. Microbiology 34(2):224-227

Ren JH, Zhang JF, Liu RX, Li YQ (2008) Study on arbuscular mycorrhizae in Taxus chinensis var. mairei. Acta Bot Bor Occi Sin 28(7):1468-1473

Rojas-Andrade R, Cerda-García-Rojas CM, FrÍas-Hernández JT, Dendooven L, Olalde-Portugal V, Ramos-Valdivia AC (2003) Changes in the concentration of trigonelline in a semi-arid leguminous plant (Prosopis laevigata) induced by an arbuscular mycorrhizal fungus during the presymbiotic phase. Mycorrhiza 13:49-52

Rosa-Mera CJD, Ferrera-Cerrato R, Alarcón A, Sánchez-Colín MJ, David OD (2011) Arbuscular mycorrhizal fungi and potassium bicarbonate enhance the foliar content of the vinblastine alkaloid in Catharanthus roseus. Plant Soil 349:367-376

Sailo GS, Bagyaraj DJ (2005) Influence of different AM-fungi on the growth, nutrition and forskolin content of Coleus forskohlii. Mycol Res 109(7):795-798

Shah V, Bhat SV, Bajwa BS, Domacur H, De SNJ (1980) The occurrence of forskolin in Labiatae. Planta Med 39:183-185

Shen XL, Guo QS, Liu ZY, Zhu GS, Liu YX (2011) Colonization progress of arbuscular mycorrhizae on tissue-cultured plantlets of Pinellia ternata. Chin J Chin Mater Med 36:93-96

Singh R, Soni SK, Kalra A (2013) Synergy between Glomus fasciculatum and a beneficial Pseudomonas in reducing root diseases and improving yield and forskolin content in Coleus forskohlii Briq. under organic field conditions. Mycorrhiza 23:35-44

Smith SE, Read DJ (1997) Mycorrhizal symbiosis. Aca-demic Press Ltd., London

Smith SE, Read DJ (2008) Mycorrhizal symbiosis, 3rd edn. Academic, London

Szakiel A, Pączkowski, Henry (2011a) Influence of environmental biotic factors on the content of saponins in plants. Phytochem Rev 10:493-502

Szakiel A, Pączkowski, Henry (2011b) Influence of environmental abiotic factors on the content of saponins in plants. Phytochem Rev 10:471-491

Teng HR, He XL (2005) Effects of different AM fungi and N levels on the flavonoid content of Bupleuruin scorzonerifolium Willd. J Shanxi Agr Sci 4:53-54 
Toussaint JP (2007) Investigating physiological changes in the aeria parts of AM plants: what do we know and where should we be heading? Mycorrhiza 17:349-353

Toussaint JP, St-Arnaud M, Charest C (2004) Nitrogen transfer and assimilation between the arbuscular mycorrhizal fungus Glomus intraradices Schenck \& Smith and Ri T-DNA roots of Daucus carota L. in an in vitro compartmented system. Can J Microbiol 50:251-260

Toussaint JP, Smith FA, Smith SE (2007) Arbuscular mycorrhizal fungi can induce the production of phytochemicals in sweet basil irrespective of phosphorus nutrition. Mycorrhiza 17:291-297

Volpin H, Elkind Y, Okon Y, Kapulnik Y (1994) A vesicular arbuscular mycorrhizal fungus (Glomus intraradices) induces a defense response in alfalfa roots. Plant Physiol 104:683-689

Wang LY, He XL (2009) The resource and spatio-temproal distribution of AM fungi from Salvia miltiorrhiza in Anguo. J Agr Univ Hebei 32(6):73-79

Wang Q, Li HQ, Du YR, Li Y, Li HW (1998) Isolation and identification of VA mycorrhizal fungi on Radix gentianae. Biotechnology $8(2): 19-22$

Wang Q, He XL, Chen TS, Dou WF (2006) Ecological research of arbuscular mycorrhizal fungi in rhizosphere of Puerraria lobata. $\mathrm{J}$ Hebei Univ 26(4):420-425

Wang DX, Lu YQ, He XL (2010) Effects of AM fungi on growth and physiological characters of Atractylodes Macrocephala under different P-applied levels. Acta Bot Bor Occi Sin 30(1):136-142

Wei GT, Wang HG (1989) Effects of VA mycorrhizal fungi on growth, nutrient uptake and effective compounds in Chinese medicinal herb Datura stramonium L. Sci Agr Sin 22(5):56-61

Wei GT, Wang HG (1991) Effect of vesicular-arbuscular mycorrhizal fungi on growth, nutrient uptake and synthesis of volatile oil in Schizonepeta tenuifolia Briq. Chin J Chin Mater Med 16(3):139-142

Wu QC, Wei QA (2008) Arbuscular mycorrhizae of Ginkgo biloba and its correlation with soil available phosphorus. J Yangtze Univ $5(3): 49-52$

Wu QS, Liu W, Zhai HF, Ye XF, Zhao LJ (2010) Influences of AM fungi on growth and root antioxidative enzymes of Trifoliate orange seedlings under salt stress. Acta Agr Univ Jiangxiensis 32(4):759-762

Xiao WJ, Yang G, Chen ML, Guo LP, Wang M (2011) AM and its application in plant disease prevention of Chinese medicinal herbs cultivation. Chin J Chin Med 36(3):252-257

Xing XK, Li Y, Yolande D (2000) Ten species of vAM fungi in five ginseng fields of Jilin province. J Jilin Agr Univ 22(2):41-46

Xing XK, Li Y, Wang Y, Zhang MP (2003) Foundation of dual cultural system of ginseng VA mycorrhiza fungi. J Jilin Agr Univ 25(2):154-157

Yang G, Guo LP, Huang LQ, Chen M (2008) Inoculation methods of AM fungi in medicinal plant. Resources Sci 30(5):778-785
Yu Y, Yu T, Wang Y, Yan XF (2010) Effect of inoculation time on camptothecin content in arbuscular mycorrhizal Camptotheca acuminate seedlings. Chin J Plant Ecol 34(6):687-694

Zeng Y, Guo LP, Hang LQ, Zhou J, Sun YZ (2007) AM and its application in TCM cultivation. World Sci Technol/Moder TCM Mater Med 9(6):83-87

Zhang MC, Jing YJ, Ma J (1990) The changing of microbial ecological types after the improvement of ginseng soil. J Jilin Agr Univ 12(4):42-46

Zhang Y, Xie LY, Xiong BQ, Zeng M, Yu D (2004) Correlation between the growth of arbuscular mycorrhizal fungi in the rhizosphere and the flavonoid content in the root of Ginkgo biloba. Mycosystema 23(1):133-138

Zhang J, Liu DH, Guo LP, Jin H, Zhou J, Yang G (2010) Effects of four AM fungi on growth and essential oil composition in rhizome of Atractylodes lancea. World Sci Technol/Moder TCM Mater Med 12(5):779-782

Zhang J, Liu DH, Guo LP, Jin H, Yang G, Zhou J (2011) Effects of arbuscular mycorrhizae fungi on biomass and essential oil in rhizome of Atractylodes lancea in different temperatures. Chin Tradi Her Drugs 42(2):372-375

Zhao JL, He XL (2011) Effects of AM fungi on drought resistance and content of chemical components in Angelica dahurica. Acta Agr Bor Occi Sin 20(3):184-189

Zhao X, Wang BW, Yan XF (2006) Effect of arbuscular mycorrhiza on camptothecin content in Camptotheca acuminate seedlings. Acta Ecol Sin 26(4):1057-1062

Zhao PJ, An F, Tang M (2007) Effects of arbuscular mycorrhiza fungi on drought resistance of Forsythia suspense. Acta Bot Bor Occi Sin 27(2):396-399

Zhao JL, Deng HY, He XL (2009) Effects of AM fungi on the quality of trueborn Angelica dahurica from Hebei province. Acta Agr Boreali-Sin 24:299-302

Zhou JH, Fan JH (2007) Effects of AM fungi on the berberine content in Phellodendron chinense seedings. North Hortic 12:25-27

Zhou N, Xia CL, Jiang B, Bai ZC, Liu GN, Ma XK (2009) Arbuscular mycorrhiza in Paris polyphylla var. yunnanensis. Chin J Chin Med 34(14):1768-1772

Zhou N, Zou L, Wang GZ, Jiang B (2010) Primary explore to relation of arbuscular mycorrhizae and its secondary metabolite steroidal saponin in Paris polyphylla. Chin J Exper Trad Med Formulae 16(16):85-88

Zubek S, Stojakowska A, Anielska T, Turnau K (2010) Arbuscular mycorrhizal fungi alter thymol derivative contents of Inula ensifolia L. Mycorrhiza 20:497-504

Zubek S, Mielcarek S, Turnau K (2012) Hypericin and pseudohypericin concentrations of a valuable medicinal plant Hypericum perforatum L. are enhanced by arbuscular mycorrhizal fungi. Mycorrhiza 22:149-156 